\title{
Critical Success Factors (CSFs) for Cloud-Based e-Learning
}

https://doi.org/10.3991/ijet.v14i01.9170

\author{
Quadri Noorulhasan Naveed, Naim Ahmad $\left.{ }^{\bowtie}\right)$ \\ King Khalid University, Kingdom of Saudi Arabia \\ nagqadir@kku.edu.sa
}

\begin{abstract}
Cloud Computing has become the dominant technology to offer unlimited computing for various social and commercial applications. Cloud computing is also being adopted at the rapid pace for e-Learning. This paper has illustrated upon the phenomenon of Cloud based e-Learning adoption in the institutes of universities and institutes of higher education. Critical success factors for the effective implementing of Cloud Based e-Learning have been identified through systematic literature review using framework of Denyer and Tranfield (2009). Further they are clustered into four dimensions namely cloud service resilience, university technological maturity, university organizational readiness and Cloud Based e-Learning imperatives. The results of this research will be helpful for policymakers and practitioners of e-Learning in implementing Cloud Based e-Learning Platform.
\end{abstract}

Keywords - Cloud Computing, e-Learning, Cloud-Based e-Learning, Universities and Institutes of Higher Education, Critical Success Factors (CSFs)

\section{Introduction}

The quick growth in the infrastructure of the Information and Communication Technology (ICT) has enhanced the area of usage \& quality in information technology (IT) applications, a massive development of Interactive web-based apps are going on in each field [1]. e-Learning has no exception, due to its vast range capacity as learning model with a lot of facility for knowledge distribution from any place, anytime to anyone, it has grown up into a widely accepted tool for the successful teaching and learning [2]. Many universities and institutes of higher education have adopted online-Learning in their teaching and learning modules, and this development continues for lifelong learning models as well [2].

The e-Learning technology can improve the process of teaching and learning by using different application of IT. The requirement of such applications is different in different geographical locations, depending upon requirement of educational institutes for new technology and support, population and financial status and condition of IT services of that location [3]. e-Learning can deliver knowledge irrespective of the geographical location of the Instructor to their Students. It can also Improve the communication between the Students and the Instructors and help Students to learn and 
utilize the e-Learning material according to their convenient time without wasting time in collecting and photocopying the e-Learning materials [4].

The changing scenario of the financial status of the world and globalization with other factors are putting pressure on universities and institutes of higher education for ensuring suitable IT applications for its teaching and learning and research undertakings [5]. Due to advancement in IT applications, there is enormous demand from the Students and Instructors for adopting new IT Applications, Instrumental for a good experience in teaching and learning. Using Cloud Computing may be one of the solutions for getting access to new IT infrastructure for fulfilling present demand with financial savings. Cloud Computing can help in developing educational software as a service for interactive Cloud Based e-Learning, online storage of the Digital Library for the use of Students and Instructors, collaborating Wikis, Blogs and connectivity of network devices for accessing the services of the Cloud Computing [5].

Cloud Computing is latest and fastest rising sectors of the IT. Its capability of geographic distribution, cost-effectiveness in the form of automated systems and open source software makes it an attractive option for educational institutes. Smaller size institutes lack financial resources to utilize full use of IT, but Cloud computing offers them the availability of quality education, particularly in underserved and distant communities. It can also allow interactive and vibrant learning experiences by enabling Students and Instructors of different geographical locations to communicate and team up for exploring new learning methods [3].

This paper introduces the phenomenon of Cloud Based e-Learning in universities and institutes of higher education. This paper will explore the critical success factors through literature review that will help in the implementation of Cloud Based eLearning. This paper is organized into the following different sections: In Section 2, the phenomenon of Cloud Based e-Learning is presented. In Section 3, Methodology to identify the critical success factors is mentioned. Section 4 gives the detail of the critical success factors. Thereafter sections are discussion on results, limitation, future research, and conclusion.

\section{Cloud Based e-Learning}

Cloud Computing has been defined by US National Institute of Standards and Technology (NIST) as "a model for enabling convenient, on-demand network access to a shared pool of configurable computing resources (e.g., networks, servers, storage, applications, and services) that can be rapidly provisioned and released with minimal management effort or service provider interaction" [NIST]. More simplified and working definition of Cloud Computing is as "A development, deployment and delivery IT model for transmitting services, products and solutions through the Internet" [6]. It helps in the utilization of resources for enhancing the scalability and the accessibility of the IT applications [2]. NIST further defined five essential characteristics of Cloud Computing such as On-demand self-service, Broad network access, Resource pooling, Rapid elasticity and Measured Service. There are three primary service delivery models such as Software as a Service (SaaS), Platform as a Service (PaaS) and 
Infrastructure as a Service. Moreover, there are four deployment models such as Private cloud, Community cloud, Public cloud and Hybrid cloud. There are multiple institutions and technologies that make it work as shown in Figure 1.

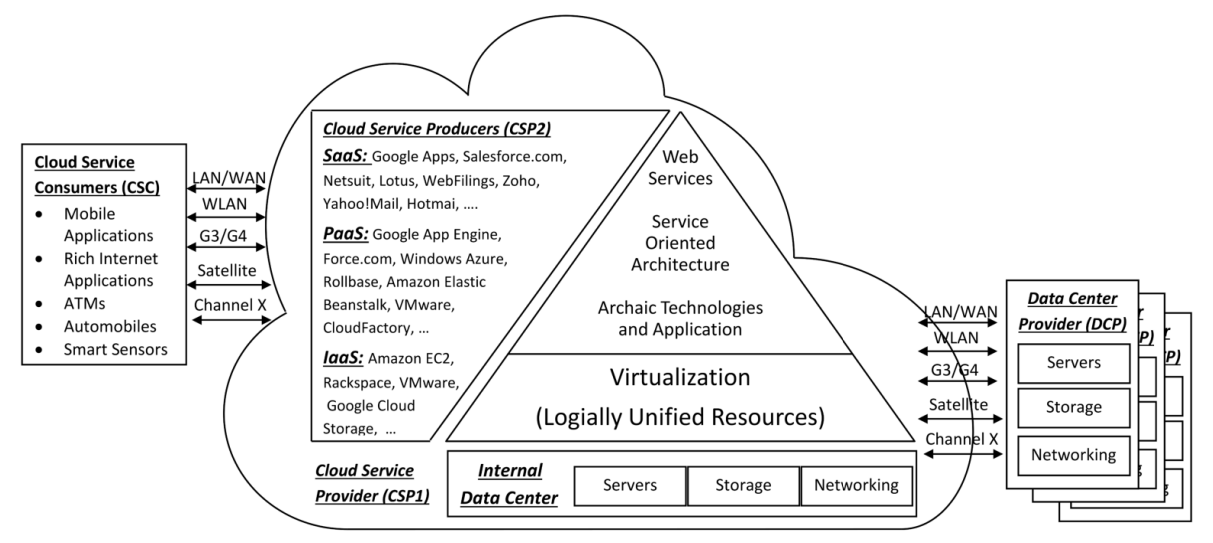

Fig. 1. Cloud Computing Environment [7]

e-Learning is the use of Information technology and services (for facilitating the educational contents to users) by connecting people (Instructors and Students) for the teaching and learning purpose [8]. e-Learning has grown an essential tool for the teaching in the classroom as well as for self-study learning and gaining new knowledge [9]. Even though e-Learning is helping a lot in knowledge transfer, still there are many limitations and inability to fulfil many requirements of learners in providing many resources [10]. For example, as the number of students are increasing the need of more physical hardware equipment, system development and more resources to troubleshoot the problems are required. The present e-Learning system has a limitation in fulfilling the dynamic scalability demand of storage and other resources [10]. This can be solved by using the cloud computing [11].

Cloud computing is a highly useful technology with a lot of advantages such as initial saving in the cost, easily availability of the data at any time, improving performance, efficiently updating the e-Learning software and benefitting for Instructors and students [12]. Both private, as well as government sectors, are looking for the use of cloud computing in a different domain such as education, healthcare and other public sectors. By taking care of the human factors and the technical factors, they can achieve more success in the use of cloud computing [13]. Use of cloud in e-Learning has been discussed in many research studies.

[14] describe the different characteristics of the present e-Learning system as well as cloud computing and presented architecture of e-Learning system by combining the features of cloud computing. [15] evaluated the adoption of cloud computing in eLearning with its advantages and disadvantages. [9] studied the effect on economy in implementing the cloud computing technology in educational services. [16] studies the benefits of combing e-Learning and cloud computing in the higher educational institutes. [17] discussed the challenges and the advantages of implementing cloud 
computing in the Malaysian institutes of higher education. These studies show clearly that the phenomenon of Cloud Based e-Learning is gaining momentum. At this juncture identification of Critical Success Factors (CSFs) for the effective implementation of Cloud Based e-Learning at universities and institutes of higher education will be very helpful. Following sections present methodology for deriving the critical success factors for Cloud Based e-Learning and describe them.

\section{Research Methodology}

Critical Success Factors are defined as "the limited number of areas in which results, if they are satisfactory, will ensure successful competitive performance for the organization" [18]. The theory of CSFs is widely used in the information systems area such as [19] and also in e-Learning area such as [20]-[22]. To identify most relevant and important CSFs for Cloud-Based e-Learning systematic literature review following five steps of were adopted:

Step 1: Question Formulation: Identification of CSFs for effective implementation of Cloud Based e-Learning.

Step 2: Locating Studies: Following Search Strings consisting of Keywords and Boolean operator of “+”, were used on Google Scholar, IEEE Xplore Digital Library, Science Direct, ACM, Springer, and Taylor \& Francis databases.

"Cloud Computing" + "e-Learning" + CSFs

"Cloud Computing" + "e-Learning" + "Critical Success Factors"

"Cloud Computing" + "e-Learning" + "Factors"

Step 3: Study selection and evaluation: Studies that were giving some important factors being considered in the adoption model or generally in the context of university and institute of higher education and cloud computing and/or e-Learning or generally, were selected and ended up with 24 articles.

Step 4: Analysis and synthesis: All the factors identified were entered in the spread sheet software and highlighted with multiple colors that appeared in multiple studies. The most frequent and significant factors were identified and clustered into four subdomains.

Step 5: Reporting and using the results: After analysis, the results were presented in the tabular format and CSFs are explained. Also, the results were discussed so as to make it easier to apply the findings of the study. 


\section{CSFs for Cloud Based e-Learning}

Table 1. CSFs for Cloud Based e-Learning

\begin{tabular}{|c|c|c|c|}
\hline Dimensions & Factors & References & No. \\
\hline \multirow[t]{3}{*}{$\begin{array}{l}\text { Cloud Service Resili- } \\
\text { ence }\end{array}$} & Cloud Data Security & $\begin{array}{l}{[23],[24],[25],[26],[27],[28],[29],[15],[31],} \\
{[32],[33],[34],[3],[36],[9],[5],[37],[38],[11]}\end{array}$ & 19 \\
\hline & $\begin{array}{l}\text { Availability \& Relia- } \\
\text { bility }\end{array}$ & {$[39],[24],[27],[32],[33],[34],[36]$} & 7 \\
\hline & $\begin{array}{l}\text { Customizable Service } \\
\text { Level Agreement }\end{array}$ & {$[23],[27],[31],[36]$} & 4 \\
\hline \multirow{3}{*}{$\begin{array}{l}\text { University Techno- } \\
\text { logical Maturity }\end{array}$} & Network Bandwidth & [23], [25], [15], [34], [3], [9], [5], [11] & 8 \\
\hline & Compatibility & {$[40],[26],[27],[31],[33]$} & 5 \\
\hline & Technical Support & {$[25],[27][26],[31]$} & 2 \\
\hline \multirow[t]{3}{*}{$\begin{array}{l}\text { University Organiza- } \\
\text { tional Readiness }\end{array}$} & Management Support & $\begin{array}{l}\begin{array}{l}\text { [40], [23], [24], [25], [15], [33], [34], [3], [5], [38], } \\
{[11]}\end{array} \\
\end{array}$ & 11 \\
\hline & $\begin{array}{l}\text { Human and Resource } \\
\text { Readiness }\end{array}$ & {$[23],[25],[9],[5],[11]$} & 5 \\
\hline & Complexity & {$[40],[27],[28]$} & 3 \\
\hline \multirow[t]{3}{*}{$\begin{array}{l}\text { Cloud Based E- } \\
\text { Learning Imperatives }\end{array}$} & \begin{tabular}{|l|} 
Cost \\
Flexibility \\
\end{tabular} & [40], [26], [27], [29], [33], [34], [9], [5], [11] & 9 \\
\hline & Ease of Use & {$[41],[28],[36]$} & 3 \\
\hline & Relative Advantage & {$[40],[27],[28]$} & 3 \\
\hline
\end{tabular}

Cloud Data Security: The risks and challenges associated during the execution of Cloud computing and usage of e-Learning data on the Cloud Computing in the Universities [28]. Using e-Learning through Cloud has more leads over traditional eLearning, It is easy to maintain security updates, privacy of the data and user information, which will not only increase the confidence in the system but also reduce the overall cost to the users [26].

Availability \& Reliability: One to the main aims of using the Cloud Computing by the Universities is its feature of Availability \& Reliability [41]. It is in using eLearning so that it should increase the Availability of the e-Learning system by detecting any failure of its services and nodes, without disturbing the e-Learning operations [26]. The technology should be Reliable and Stable during the peak hours of the usage [3].

Customizable Service Level Agreement: SLA is the Service level agreements between the service providers and the e-Learning units of the Universities as users. Universities need to take Cloud services according to their need and requirements only [23].

Network Bandwidth: The Internet speed and data accessibility to the users is the major requirement of Cloud based e-Learning [25]. Good bandwidth helps users to use unlimited CPU and vast storage space of the system [28].

Compatibility: It is the ability of the Cloud Computing system to work together with the Data, documents and the e-Learning System of the universities [43]. 
Technical Support: Training and Technical support to the user is important in the success of any system. Many studies found that support and training play significant role in the technology acceptance [41].

Management Support: The execution of Cloud based e-Learning in the universities is strategically depend on the support and attitude of the University's top Management. Their awareness, understanding, consent and releasing of the funds are important in migrating or implementing the cloud-based services [23].

Human and Resource Readiness: The readiness of the Students, Instructors and the Technical staff to use the services of the Cloud Computing and IT application as well as the computing resources such as e-Learning applications on computer, storage servers and other necessary network services come under this CSF [25].

Complexity: It is the degree of difficulty in utilization of Cloud based e-Learning system. It is considered as Barriers of the system, which needs to be identified in the current system and solved [40].

Cost Flexibility: Cloud computing is an emerging information technology being used in the field of Education industry due to flexible pricing model. Its features of automated system based on open source system and reduced cost in usage of the system, are helping to achieve this [3].

Ease of Use: Simplicity in the system develops the users' ability to use the system for enhancing their performance. Usage of the system increase the performance but the evaluation of the effort it will take to use such a system is also important [28]. User's degree of believe about the easiness of the system helps them in the usage of the system.

Relative Advantage: It is the degree of user's trust in the Cloud based e-Learning system and will be more useful for their success in the academic studies and performance [41].

\section{$5 \quad$ Discussion on Results}

In the present context of Knowledge society and economy, e-Learning has become an economical and viable tool to educate the masses. The success of e-Learning is dependent upon the creation of virtual platforms that replicate the advantages of traditional means of education at one hand and circumvent its pitfalls with the help of technology. In order to achieve this Cloud Based e-Learning holds the solution that fulfills the need of on-demand and infinite computing resources. This study has identified twelve most important CSFs essential for effective implementation of Cloud Based e-Learning categorized into four domains.

- Cloud Service Resilience: Cloud service providers and producers have to ensure the security of the complete environment. Any lapses in the security can lead to mistrust from all stakeholders. Similarly, as the convenience is the integral factor in the e-Learning therefore the availability and reliability of the services are paramount. Also, the providers must offer customizable service level agreement as the size of students will vary institution to institution and course to course hence the service. 
- Institutions' Technological Maturity: In order to avail all the features of Cloud Based e-Learning institutions' must have optimum level of network bandwidth. Also, the Institutions' e-Learning Applications must be compatible with the Cloud's systems. Also, one key factor is the efficient technical support for all the stakeholders.

- Institutions' Organizational Readiness: Top management support is very essential for any major IS adoption so is the case with Cloud Based e-Learning also.

Also, the readiness of students, instructors and technical staff to use Cloud Computing and IT applications along with computing resources of e-Learning is essential. On the other hand, the complexity in the current system should be simplified.

- Cloud Based e-Learning Imperatives: This dimension addresses essential factors that are needed to close the loop of ecological cycle of Cloud based e-Learning. The cost flexibility is one of the primary reasons to move on it and should be ascertained in the letter and spirit. Similarly, the system should remain easy to use for the most complex tasks. Lastly, there should be perceivable relative advantage to move onto the Cloud-Based e-Learning System.

\section{Limitation, Future Research and Conclusion}

This research has illustrated upon the phenomenon of Cloud Based e-Learning in universities and institutes of higher education and found it to be in the growth stage. CSFs are very instrumental to achieve success in any domain. This paper has identified twelve CSFs and clustered them into four sub-domains such as cloud service resilience, university technological maturity, university organizational readiness and Cloud Based e-Learning imperatives. The CSFs will be very helpful for the implementation of Cloud Based e-Learning Platforms. In Future studies most important Barriers or challenges for Cloud Based e-Learning can be identified. Similarly, the relationship of CSFs and Barriers may be established to priorities and to know the influence of them. Additionally, these CSFs have been identified through systematic literature review and may further be verified through survey and statistical analysis.

\section{$7 \quad$ References}

[1] He Z. and Yue J., "Integrating e-Learning system based on cloud computing," Granul. Comput. (GrC), 2012 IEEE International Conference on, IEEE, 2012. https://doi.org/10.1109/GrC.2012.6468663

[2] Dong B., Zheng Q., Qiao M., Shu J., and Yang J., "BlueSky cloud framework: An eLearning framework embracing cloud computing," Lect. Notes Comput. Sci. (including Subser. Lect. Notes Artif. Intell. Lect. Notes Bioinformatics), vol. 5931 LNCS, pp. 577582, 2009.

[3] Ketel M., "e-Learning in a Cloud Computing Environment," Ieee Southeastcon 2014, pp. 1-2, 2014. https://doi.org/10.1109/SECON.2014.6950728

[4] Kihara T. and Gichoya D., "Use of cloud computing platform for e-Learning in institutions of higher learning in Kenya," 2014 IST-Africa Conf. Proc., pp. 1-6, 2014. 
[5] Masud A. H. and Huang X., "A novel approach for adopting cloud-based e-Learning system," Proc. - 2012 IEEE/ACIS 11th Int. Conf. Comput. Inf. Sci. ICIS 2012, pp. 37-42, 2012.

[6] Abdel-Basset M., Mohamed M., and Chang V., "NMCDA: A framework for evaluating cloud computing services," Futur. Gener. Comput. Syst., vol. 86, pp. 12-29, 2018. https://doi.org/10.1016/j.future.2018.03.014

[7] Ahmad N., "Cloud Computing: Technology, Security Issues and Solutions," Anti-Cyber Crimes (ICACC), 2017 2nd International Conference on, IEEE, 2017. https://doi.org/10.1109/Anti-Cybercrime.2017.7905258

[8] Arafat S., Aljohani N., Abbasi R., Hussain A., and Lytras M., "Connections between ELearning, web science, cognitive computation and Social Sensing, and their relevance to learning analytics: A preliminary study," Comput. Human Behave, 2018. https://doi.org/10.1016/j.chb.2018.02.026

[9] Boja C., Pocatilu P., and Toma C., "The Economics of Cloud Computing on Educational Services," Procedia-Soc. Behav. Sci., vol. 93, pp. 1050-1054, 2013. https://doi.org/10.1016/j.sbspro.2013.09.328

[10] Ewuzie I. and Usoro A., "Exploration of cloud computing adoption for e-Learning in higher education,” Proc. - IEEE 2nd Symp. Netw. Cloud Comput. Appl. NCCA 2012, pp. 151154, 2012. https://doi.org/10.1109/NCCA.2012.19

[11] Xiao L. and Wang Z., "Cloud computing: A new business paradigm for e-Learning," Proc. - 3rd Int. Conf. Meas. Technol. Mechatronics Autom. ICMTMA 2011, vol. 1, pp. 716719,2011

[12] Riahi G., "e-Learning systems based on cloud computing: A review," Procedia Comput. Sci., vol. 62, no. Scse, pp. 352-359, 2015.

[13] Amron M. T., Ibrahim R., and Chuprat S., "A Review on Cloud Computing Acceptance Factors," Procedia Comput. Sci., vol. 124, pp. 639-646, 2017. https://doi.org/10.1016/j.procs.2017.12.200

[14] Masud A. H. and Huang X., "An e-Learning System Architecture based on Cloud Computing,” Int. Sch. Sci. Res. Innov., vol. 6, no. 2, pp. 255-259, 2012.

[15] Machii J. K., and Kyalo J. K., "Assessment of Cloud Computing Adoption for e-Learning by Institutions of Higher Learning in Nairobi County, Kenya," Int. J. Sci. Res. Innov. Technol. ISSN, vol. 3, no. 2, pp. 9-20, 2016.

[16] Klimova B. and Maresova P., "Cloud computing and e-Learning and their benefits for the institutions of higher learning," 2016 IEEE Conf. e-Learning, e-Management e-Services, IC3e 2016, pp. 75-78, 2017.

[17] Shahzad A., Golamdin A. G., Azizi N., Othman I. D., and Abdullah Y., "Opportunity and Challenges using the Cloud Computing in the Case of Malaysian Higher Education Institutions," Int. J. Manag. Sci. Inf. Technol. Issue, no. 20, pp. 1-18, 2016.

[18] Rockart J. F. and Sloan W. P., "Information Systems Executive: A Critical Success Factors Perspective," 1982.

[19] Ahmad N., Haleem A., and Syed A. A., "Compilation of Critical Success Factors in Implementation of Enterprise Systems: A Study on Indian Organisations," Glob. J. Flex. Syst. Manag., vol. 13, no. 4, pp. 217-232, 2012. https://doi.org/10.1007/s40171-013-0019-8

[20] Naveed Q. N., Muhammad A., Sanober S., Qureshi M. R. N., and Shah A., "A Mixed Method Study for Investigating Critical Success Factors (CSFs) of e-Learning in Saudi Arabian Universities,” Int. J. Adv. Comput. Sci. Appl., vol. 8, no. 5, pp. 171-178, 2017.

[21] Quadri N. N., Muhammed A., Sanober S., Qureshi M. R. N., and Shah A., "Barriers Effecting Successful Implementation of e-Learning in Saudi Arabian Universities," Int. J. 
Emerg. Technol. Learn., vol. 12, no. 06, pp. 94-107, 2017. https://doi.org/10. 3991/ijet.v12i06.7003

[22] Naveed Q. N., Qureshi M. R. N., Alsayed A. O., Muhammad A., Sanober S., and Shah A., "Prioritizing Barriers of e-Learning for Effective Teaching-Learning using Fuzzy Analytic Hierarchy Process (FAHP)," in 4th IEEE International Conference on Engineering Technologies and Applied Sciences (ICETAS) 2017, 2017. https://doi.org/10.1109/ICETAS.2017.8277855

[23] Alharthi A., Alassafi M. O., Walters R. J., and Wills G. B., "An exploratory study for investigating the critical success factors for cloud migration in the Saudi Arabian higher education context," Telemat. Informatics, vol. 34, no. 2, pp. 664-678, 2017. https://doi.org/10.1016/j.tele.2016.10.008

[24] Kassim S. S., Razak A., and Husin C., "Risk Tolerance and Trust Issues in Cloud-based," in ACM Proceedings of the Second International Conference on Internet of things and Cloud Computing, 2017, p. 73. https://doi.org/10.1145/3018896.3018973

[25] Amron M. T., Ibrahim R., and Chuprat S., "A Review on Cloud Computing Acceptance Factors,” Procedia Comput. Sci., vol. 124, pp. 639-646, 2017. https://doi.org/10.1016/j.procs.2017.12.200

[26] El-Mhouti A., Erradi M., and Nasseh A., "Using cloud computing services in e-Learning process: Benefits and challenges," Educ. Inf. Technol., pp. 1-17, 2017.

[27] Hwang B. N., Huang C. Y., and Yang C. L., "Determinants and their causal relationships affecting the adoption of cloud computing in science and technology institutions," Innovation, vol. 18, no. 2, pp. 164-190, 2016. https://doi.org/10.1080/14479338.2016.1203729

[28] Sabi H. M., Uzoka F. E., Langmia K., and Njeh F. N., "Conceptualizing a model for adoption of cloud computing in education,” Int. J. Inf. Manage., vol. 36, no. 2, pp. 183-191, 2016. https://doi.org/10.1016/j.ijinfomgt.2015.11.010

[29] ABBA A. and Bakon K. A., "An Overview Of Cloud Computing Platform For e-Learning In Institutions Of Higher Learning In Nigeria,” Int. J. Inf. Syst. Eng., vol. 4, no. 1, pp. 1-6, 2016.

[30] Ahmed F. F., "Comparative Analysis for Cloud Based e-Learning," Procedia Comput. Sci., vol. 65, no. Iccmit, pp. 368-376, 2015.

[31] Bote-lorenzo M. L., Eduardo G., and Cano-parra R., "Computers \& Education Cloud computing and education : A state-of-the-art survey," vol. 80, pp. 132-151, 2015.

[32] Mokhtar S. A., Ali S. H. S., Al-Sharafi A., and Aborujilah A., "Organizational factors in the adoption of cloud computing in e-Learning," Proc. - 3rd Int. Conf. Adv. Comput. Sci. Appl. Technol. ACSAT 2014, pp. 188-191, 2014. https://doi.org/10.1109/ACSAT.2014.40

[33] Ketel M., "Cloud services for e-Learning," Proc. 2014 ACM Southeast Reg. Conf. - ACM SE '14, pp. 1-4, 2014. https://doi.org/10.1145/2638404.2638504

[34] Okai S., Uddin M., Arshad A., Alsaqour R., and Shah A., "Cloud computing adoption model for universities to increase ICT proficiency," SAGE Open, vol. 4, no. 3, pp. 1-10, 2014. https://doi.org/10.1177/2158244014546461

[35] Masud M. A. H. and Huang X., "An e-Learning system architecture based on cloud computing," System, vol. 6, no. 2, pp. 74-78, 2012.

[36] Aljenaa E., Al-Anzi F. S., and Alshayeji M., "Towards an efficient e-Learning system based on cloud computing," Proc. Second Kuwait Conf. e-Services e-Systems - KCESS '11, pp. 1-7, 2011. https://doi.org/10.1145/2107556.2107569

[37] Watfa M., "Cloud computing and e-Learning: Potential pitfalls and benefits," 2016 6th Int. Conf. Innov. Comput. Technol. INTECH 2016, pp. 140-144, 2017. 
[38] AlAjmi Q., Arshah R. A., Kamaludin A., Sadiq A. S., and Al-Sharafi M. A., "A conceptual model of e-Learning based on cloud computing adoption in higher education institutions," 2017 Int. Conf. Electr. Comput. Technol. Appl., pp. 1-6, 2017.

[39] Arpaci I., "Antecedents and consequences of cloud computing adoption in education to achieve knowledge management," Comput. Human Behave, vol. 70, pp. 382-390, 2017. https://doi.org/10.1016/j.chb.2017.01.024

[40] Nguyen T. D., Nguyen D. T., and Cao T. H., "Acceptance and use of information system: e-Learning based on cloud computing in Vietnam," Lect. Notes Comput. Sci. (including Subser. Lect. Notes Artif. Intell. Lect. Notes Bioinformatics), vol. 8407 LNCS, no. 4960, pp. 139-149, 2014.

\section{Authors}

Quadri Noorulhasan Naveed is working as a Lecturer in the College of Computer Science, King Khalid University, Saudi Arabia. He has completed his graduation and Masters from Dr. BAMU, India and pursuing PhD in Information Technology from International Islamic University Malaysia (IIUM) Kuala Lumpur. He has also worked as IT Engineer in Saudi Aramco and Bank Riyad of Saudi Arabia. His current area of research are Cloud Computing, e-Learning and Cloud based e-Learning systems. He has publications in refereed/indexed international journals and IEEE sponsored conferences.

Naim Ahmad did PhD in Enterprise Systems from Aligarh Muslim University, a central university in India and MS in Computer and Information Sciences from University of South Alabama (USA), Mobile, US. He worked at USA as a research assistant at US DOE funded project and also as a graduate assistant. He has taught as an assistant professor at Management and Engineering colleges in India for seven years. He was awarded Upsilon Pi Epsilon Award for Computing Excellence in 2003 at USA. He has publications in refereed international journals, conferences and book chapter. He has been faculty member at King Khalid University, Saudi Arabia since 2013 and his current research interests are Enterprise Systems, Internet of Things, Cloud Computing and e-Learning.

Article submitted 05 July 2018. Final acceptance 08 August 2018. Fiknal. Version published as submitted by the authos. 